\title{
Synthesis and study of poly(3-hexylthiophenes) and poly(3- dodecylthiophenes) containing halogen and sulfur substituents in the $\omega$-position of the side chain
}

\author{
Martin Pomerantz, * Lixin (Martha) Liu, and Xinnong (Simon) Zhang \\ Department of Chemistry and Biochemistry, Box 19065, The University of Texas at Arlington, \\ Arlington, TX 76019-0065 USA \\ E-mail:pomerantz@uta.edu
}

Dedicated to Professor Henry Shine on the occasion of his $80^{\text {th }}$ birthday

(received 16 Jun 03; accepted 22 Oct 03; published on the web 05 Dec 03)

\begin{abstract}
Poly[3-(6-bromohexyl)thiophene] (1) and poly[3-(12-bromododecyl)thiophene] (2) were synthesized by chemical polymerization of their respective monomers, 3 and $\mathbf{4}$, using $\mathrm{FeCl}_{3}$. NMR spectroscopy showed $81 \%$ of head-to-tail couplings and GPC showed $\bar{M}_{n}=51,500$ and 91,100 with PDIs of 5.2 and 1.7 for 1 and 2, respectively. Conductivities of the $\mathrm{I}_{2-}$ and $\mathrm{FeCl}_{3-}$ doped 1 were 18 and $7.5 \mathrm{~S} \mathrm{~cm}^{-1}$ and for 2 were 32 and $46 \mathrm{~S} \mathrm{~cm}^{-1}$, respectively. Poly[3-(6iodohexyl)thiophene] (8) was prepared by $\mathrm{S}_{\mathrm{N} 2}$ displacement (>97\%), using NaI, on 1. Poly[6-(3thienyl)-1-hexyl $S$-thioacetate] (10a) and poly[12-(3-thienyl)-1-dodecyl $S$-thioacetate] (10b) were prepared from 1 by post-polymerization $\mathrm{S}_{\mathrm{N} 2}$ reactions. They were insoluble in organic solvents and had ${ }^{13} \mathrm{C}$ CP-MAS NMR spectra consistent with the structures. Reaction of 1 with thiourea followed by basic hydrolysis gave poly[3-(6-mercaptohexyl)thiophene] (11). This thiol functionalized polymer was also insoluble in common organic solvents and it, too, had a ${ }^{13} \mathrm{C} \mathrm{CP}-$ MAS NMR spectrum consistent with the structure. Polymers 10a and 11 showed pressed pellet conductivities of $4 \times 10^{-5}$ and $2.3 \times 10^{-2} \mathrm{~S} \mathrm{~cm}^{-1}$ when doped with $\mathrm{FeCl}_{3}$, respectively and $8 \times 10^{-5}$ and $0.44 \mathrm{~S} \mathrm{~cm}^{-1}$ when doped with $\mathrm{I}_{2}$, respectively. TGA of polymers $\mathbf{1}, \mathbf{8}$ and 11 showed thermal decomposition in two stages.
\end{abstract}

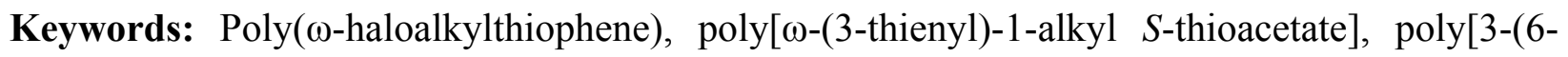
mercaptohexyl)thiophene], ${ }^{13} \mathrm{C}$ CP-MAS NMR

\section{Introduction}

Because of their electrical conductivity and electroluminescent properties, polythiophenes have been under intense investigation for many years. A number of 3-substituted polythiophenes, both 
regiorandom and regioregular, have been prepared by chemical or electrochemical oxidation of appropriately 3-substituted thiophenes. ${ }^{1-3}$ In this paper we report on the preparation of poly[3-(6bromohexyl)thiophene] and poly[3-(12-bromododecyl)thiophene] (2) by direct chemical polymerization of the monomers, 3-(6-bromohexyl)thiophene (3) and 3-(12bromododecyl)thiophene (4) and on their conversion to other polythiophene derivatives by displacement of the bromine leaving group. This is a follow-up of our preliminary report describing the preparation of these two polymers 1 and $\mathbf{2}$ using ferric chloride oxidative polymerization of monomers 3 and $4 .{ }^{4,5}$ About the same time as our initial preliminary report ${ }^{4}$ Iraqi et al. reported on the preparation of head-to-tail regioregular polymer $1{ }^{6}$ The following year $\mathrm{Ng}$ et al. reported on the synthesis of three poly[3-( -bromoalkyl)thiophene] polymers ${ }^{7}$ using our reported methodology but failed to cite the prior publications. ${ }^{4-6}$

Very recently a paper appeared reporting on head-to-tail regioregular polymer $\mathbf{1}$ and on several other polymers derived from $\mathbf{1}$ by post-polymerization reactions where the bromine acts as a leaving group. ${ }^{8}$

\section{Results and Discussion}

\section{Bromine and iodine containing polymers}

The monomers, (6-bromohexyl)thiophene (3) and 3-(12-bromododecyl)thiophene (4), were prepared as shown in Scheme 1 using a modification of the synthesis reported by Bäuerle. ${ }^{9}$ The synthetic steps we employed were similar to those of Bäuerle except for the alcohol protecting group. We used the tetrahydropyranyl (THP) protecting group whereas Bäuerle used the $p$ methoxyphenyl group. 1-Bromo-6-(2-tetrahydropyranyloxy)hexane and 1-bromo-12-(2tetrahydropyranyloxy)dodecane were prepared by a modification of the literature procedure from the corresponding $\omega$-bromo-1-alkanol. ${ }^{10,11}$ Amberlyst $\mathrm{H}-15,{ }^{12}$ an ion exchange resin containing strongly acidic $-\mathrm{SO}_{3} \mathrm{H}$ groups, was used and yields of $90 \%$ and $97 \%$ of $\mathbf{5 a}$ and $\mathbf{5 b}$, respectively, were obtained. Coupling of the Grignard reagents obtained from 5a and 5b with 3bromothiophene using $\mathrm{Ni}(\mathrm{dppp}) \mathrm{Cl}_{2}$ [dppp=1,2-bis(diphenylphosphino)propane] as catalyst gave compounds 6a and 6b. Methanolysis, using Amberlyst H-15, produced 6-(3-thienyl)-1-hexanol (7a) and 12-(3-thienyl)-1-dodecanol (7b) and conversion of $-\mathrm{OH}$ to $-\mathrm{Br}$ to give 3 and $\mathbf{4}$ was carried out using $\mathrm{PBr}_{3}$ following the procedure of Smith, ${ }^{13}$ and also with $\mathrm{HBr}$ in the case of $\mathbf{7 b}$. For the oxidative polymerization, 4 equivalents of anhydrous $\mathrm{FeCl}_{3}$ were used to give polymers 1 and $\mathbf{2}$ (Scheme 1) after dedoping with $\mathrm{NH}_{4} \mathrm{OH}$. $\mathbf{1}$ and $\mathbf{2}$ were soluble in common organic solvents such as chloroform, toluene, THF, DMF and DMSO.

The chemical structures and degrees of regioregularity of $\mathbf{1}$ and $\mathbf{2}$ were studied by ${ }^{1} \mathrm{H}$ and ${ }^{13} \mathrm{C}$ NMR spectroscopy. The ${ }^{1} \mathrm{H}$ NMR spectra show two resonances at $\delta 2.83$ and 2.60 for 1 and $\delta$ 2.81 and 2.60 for 2 . On the basis of the shielding effect of the thiophene ring and comparison with the spectrum of poly(3-hexylthiophene) ${ }^{14}$ and poly(3-dodecylthiophene $)^{15}$ the peaks 


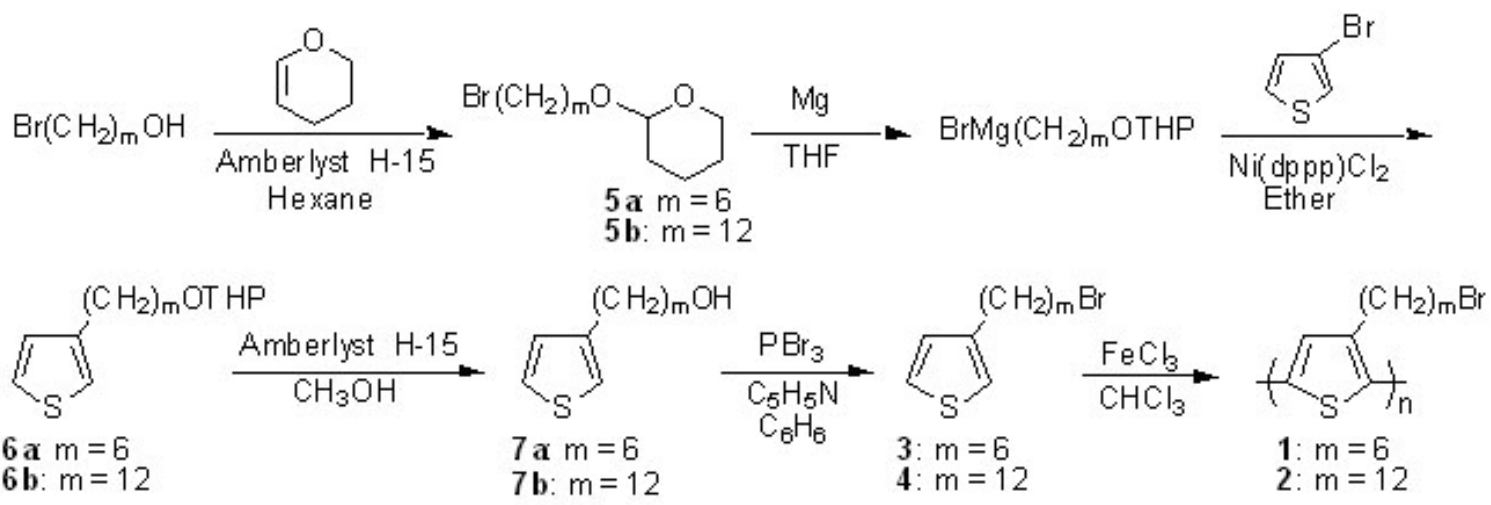

\section{Scheme 1}

at $\delta 2.60$ and $\delta 2.83 / 2.81$ were assigned to the $\mathrm{CH}_{2}$ groups adjacent to the thiophene ring for the head-to-head $(\mathrm{HH})$ and head-to-tail (HT) configurations, respectively. Furthermore, the intensity ratio of these two peaks suggests that both 1 and 2 consist of $81 \%$ HT dyads and 19\% HH dyads. Analysis of the spectral region at $\delta$ 6.98-7.06 provides additional configurational and regiochemical information on the polymers. The four resonances for $\mathbf{1} / \mathbf{2}$ at $\delta 6.98,7.01,7.03$ and 7.06/7.05 are assigned to HT-HT, HT-TT, HT-HH, TT-HH triad configurations, respectively. ${ }^{14,15}$ It should be noted that the HT-HT peak at $\delta 6.98$ compares quite favorably with the value of $\delta$ 6.98 reported by Iraqi, et al. ${ }^{6}$ and $\delta 6.95$ reported recently by Zhai, et al. for the HT-regioregular version of $1 .{ }^{8}$ In addition, the peaks reported by $\mathrm{Ng}$, et al. agree with those we observed and, while in our hands the HT dyad is $81 \%$ of the polymer, they report that their polymer 1 has only $68-73 \%$ HT dyads. ${ }^{7}$ The reasons for their lower regioregularity is not clear. The relative percentage of triad configurations and $1 \mathrm{H} \mathrm{NMR}$ data for polymers $\mathbf{1}$ and $\mathbf{2}$ are shown in Table 1. The signal for the methylene protons linked to the $-\mathrm{Br}$ group are at $\delta 3.43$ for $\mathbf{1}$ and 3.39 for 2 . There is, in addition, a fairly small $(<5 \%)$ broad peak centered at $\delta 0.86 \mathrm{ppm}$ for both 1 and 2 which corresponds to a terminal methyl group which must have been produced by reduction of the $\omega-\mathrm{CH}_{2} \mathrm{Br}$ in one of the synthetic steps. The structure of the polymers was also revealed in part by the ${ }^{13} \mathrm{C}$ NMR spectra. The signals at $\delta 139.6$ and 139.8 are assigned to the carbons in position 3 of the thiophene rings containing the alkyl substituents in $\mathbf{1}$ and $\mathbf{2}$, respectively, the signals at $\delta 133.7$ and 133.6 to the carbon in position 5, those at $\delta 130.6$ and 130.4 to the carbons in position 2 and those at $\delta 128.7$ and 128.6 to the unsubstituted carbons at position 4 , analogous to the assignments that have been made for poly(alkylthiophenes) by Hotta, et al. ${ }^{16}$

Table 1. Relative percentage and ${ }^{1} \mathrm{H}$ NMR spectral data for triads of polymers $\mathbf{1} / \mathbf{2}$

Triad Config. $\quad \delta_{1_{\mathrm{H}}} \quad$ Rel. $\%$



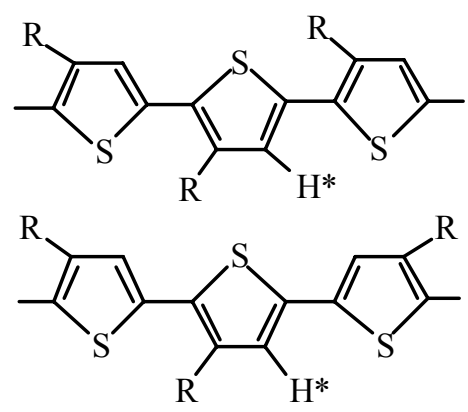

\begin{tabular}{lll}
\hline HT-HT & $6.98 / 6.98$ & $58 / 59$
\end{tabular}

HT-TT $\quad 7.01 / 7.01 \quad 15 / 15$

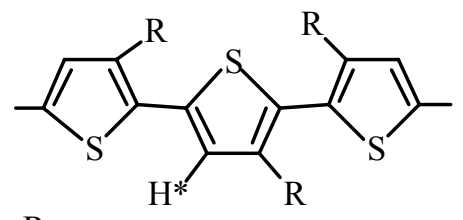

HT-HH $\quad 7.03 / 7.03 \quad 11 / 13$

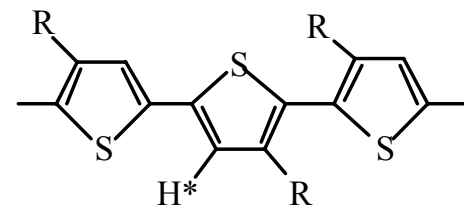

TT-HH $\quad 7.06 / 7.05 \quad 16 / 13$

Number-average molecular weights, $\overline{\mathrm{M}}_{\mathrm{n}}$, obtained by gel permeation chromatography (GPC) using polystyrene standards, for $\mathbf{1}$ and $\mathbf{2}$ were 51,500 and 91,100 with polydispersities of 5.2 and 1.7 , respectively. This is to be compared with the significantly lower number average molecular weights of 12,300-23,400 obtained by $\mathrm{Ng}$, et al. for $\mathbf{1}$ also using $\mathrm{FeCl}_{3}$ polymerization. ${ }^{7}$ Films of 1 and 2 were deep red/burgundy in color with very similar UV-vis absorption maxima at $492 \mathrm{~nm}$ and $505 \mathrm{~nm}$, respectively, and THF solutions of these two polymers also showed similar absorption spectra with $\lambda_{\max }$ of 436 and $438 \mathrm{~nm}$, respectively, all close to the values reported for poly(3-hexylthiophene) ${ }^{17-19}$ and poly(3-dodecylthiophene) ${ }^{19}$ prepared using $\mathrm{FeCl}_{3}$. The fluorescence properties of $\mathbf{1}$ and $\mathbf{2}$ were also examined. THF solutions of $\mathbf{1}$ and $\mathbf{2}$ showed emission maxima at 573 and $576 \mathrm{~nm}$ while films cast from THF showed maxima at 670 and 680 $\mathrm{nm}$, respectively. The UV-vis maxima reported by $\mathrm{Ng}$, et al. was $434 \mathrm{~nm} \mathrm{in} \mathrm{CHCl}_{3}$ solution and $488 \mathrm{~nm}$ for the film while the fluorescence maximum reported was $558 \mathrm{~nm}$ for a film of $\mathbf{1}^{7}$ These values show that the polymers prepared here have significantly greater conjugation lengths than those prepared by Ng.

The deep red/burgundy polymer films of $\mathbf{1}$ and $\mathbf{2}$ turned dark blue upon doping with iodine and $0.05 \mathrm{M} \mathrm{FeCl}_{3}$ in dry nitromethane. Doping of 1 with $\mathrm{I}_{2}$ gave a 4-point probe electrical conductivity of $\sigma=18 \mathrm{Scm}^{-1}$ while the $\mathrm{FeCl}_{3}$-doped polymer showed $\sigma=7.5 \mathrm{Scm}^{-1}$. Films of 2 gave somewhat higher conductivities. With $\mathrm{I}_{2}$ doping $\sigma=32 \mathrm{Scm}^{-1}$ and with $\mathrm{FeCl}_{3}$ doping $\sigma=46$ $\mathrm{Scm}^{-1}$. Ng, et al. reported iodine doped conductivities for 1 of 7.9-8.2 $\mathrm{Scm}^{-1}$.

In order to investigate the effectiveness of $\mathrm{S}_{\mathrm{N} 2}$ type displacements on these bromo polymers we examined the displacement of bromide by iodide using polymer 1. Since the polymer was soluble in $\mathrm{CHCl}_{3}$ but insoluble in acetone and the displacement reaction (Finkelstein reaction) ${ }^{20}$ is generally run in acetone where $\mathrm{NaI}$ is soluble, but it is insoluble $\mathrm{CHCl}_{3}$, it was determined that a 3.8:1 (v/v) mixture of $\mathrm{CHCl}_{3}$ and acetone would keep the reactants in solution. In order to see 
if the displacement reaction went to completion and produced poly[3-(6-iodohexyl)thiophene] (8) ${ }^{1} \mathrm{H}$ NMR spectra were examined. The peak in 1 at $\delta 3.43$ was replaced by a peak at $\delta 3.21$ due to the hydrogen atoms on the carbon $\alpha$ - to the halogen. Integration of the peak at $\delta 3.21 \mathrm{vs}$ the area around $\delta 3.43$ showed that the displacement

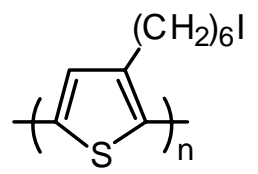

8

had occurred to at least $97 \%$ completion. Figure 1 shows the ${ }^{1} \mathrm{H}$ NMR spectra of $\mathbf{1}$ and $\mathbf{8}$. This $97 \%$ displacement is larger than the $87 \%$ reported by Iraqi et al. ${ }^{6}$ in displacement on the HTregioregular version of $\mathbf{1}$ with a carboxylate nucleophile and is similar to the report of Zhai, et al. ${ }^{8}$

\section{Sulfur containing polymers}

Approaches to the synthesis of sulfur containing polymers included attempted polymerization of sulfur containing monomers and displacement reactions on the bromoalkyl substituted polythiophenes. Initially we prepared 6-(3-thienyl)-1-hexyl S-thioacetate (9a) and 12-(3-thienyl)1-dodecyl $S$-thioacetate (9b) by displacement on bromoalkyl monomers 3 and $\mathbf{4}$ using potassium thioacetate in ethanol.

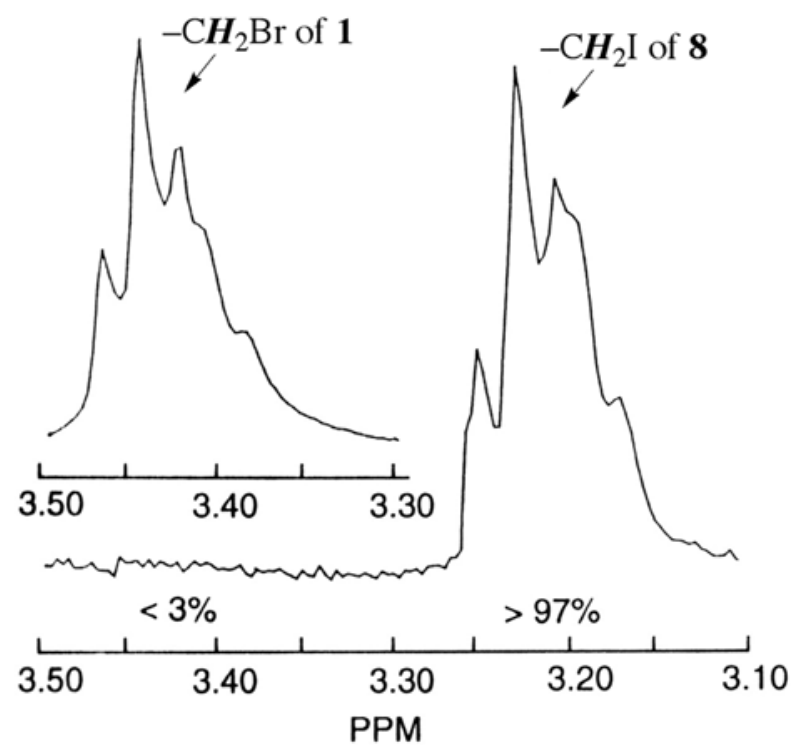

Figure 1. ${ }^{1} \mathrm{H}$ NMR spectra of 1 and $\mathbf{8}$.

Polymerization was carried out using 4 equivalents of anhydrous $\mathrm{FeCl}_{3}$ in $\mathrm{CHCl}_{3}$ (Scheme 2). The polymers precipitated and were washed with $\mathrm{MeOH}$ and dedoped with $\mathrm{NH}_{4} \mathrm{OH}$ or hydrazine 
to give red-orange solids of 10a and 10b. Surprisingly, it was found that both $\omega-\mathrm{SCOCH}_{3}$ functionalized polyalkylthiophenes $\mathbf{1 0 a}$ and $\mathbf{1 0 b}$ were insoluble in $\mathrm{CHCl}_{3}, \mathrm{THF}$, DMSO, $\mathrm{CH}_{3} \mathrm{OH}$, toluene, $\mathrm{o}$ - dichlorobenzene and tetramethylene sulfone, and only very slightly

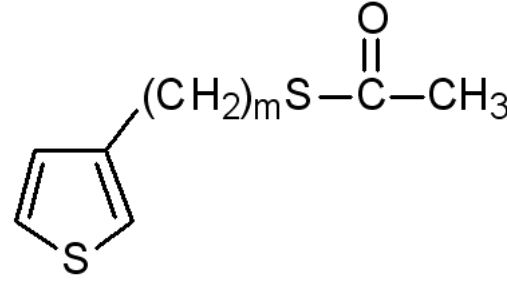

9a: $m=6$

$9 \mathrm{~b}: \mathrm{m}=12$

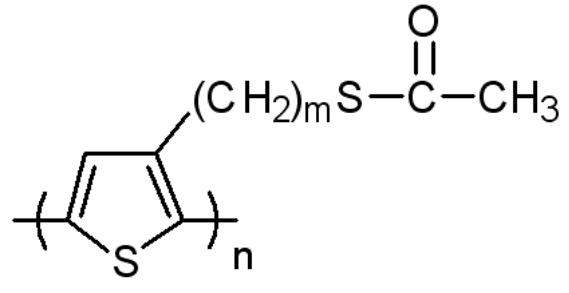

$10 \mathrm{a}: \mathrm{m}=6$

10b: $m=12$

\section{Scheme 2}

soluble in boiling thiophene $\left(84{ }^{\circ} \mathrm{C}\right)$. The reasons for the insolubility of these polymers is unknown. However, since Zhai, et al. report that HT-regioregular 10a is soluble in organic solvents, the insolubility of the samples we prepared by $\mathrm{FeCl}_{3}$ oxidation may be due to a higher molecular weight. As discussed above, the number average molecular weights of $\mathbf{1}$ and $\mathbf{2}$ were 51,500 and 91,100 respectively whereas that reported for the HT-regioregular 1 was 15,00018,000 using a lower monomer concentration or 25,000-30,000 using a higher monomer concentration. ${ }^{8}$ Thus, our molecular weight was at least double those reported by Zhai, et al. ${ }^{8}$ for $\mathbf{1}$ and are 3-4 times that for polymer 2. Polymers 10a and 10b were characterized by IR and ${ }^{13} \mathrm{C}$ CP-MAS NMR spectroscopy along with elemental analysis. Thus, for example, 10a showed the ring $\mathrm{C}-\mathrm{H}$ stretch at $3058 \mathrm{~cm}^{-1}$, the aliphatic $\mathrm{C}-\mathrm{H}$ stretching at 2852 and $2926 \mathrm{~cm}^{-1}$ and the carbonyl stretch at $1688 \mathrm{~cm}^{-1}$. The ${ }^{13} \mathrm{C} \mathrm{CP}-\mathrm{MAS}$ spectra of 10a and 10b are shown in Figure 2. The spectra are consistent with the structures in that the integrated ratios of the aromatic peaks (at $\delta \approx 120-145$ ) to aliphatic peaks (at $\delta \approx 20-45$ ) are 0.54:1.00 for 10a and 0.26:1.00 (including spinning side-bands) for $\mathbf{1 0 b}$. The theoretical integrated ratios should be 0.57:1.00 and 0.31:1.00 for 10a and 10b respectively. The pressed pellet conductivities for polymer 10a were $\sigma=4 \times 10^{-5}$ $\mathrm{Scm}^{-1}$ doped with $\mathrm{FeCl}_{3}$ and $\sigma=8 \times 10^{-5} \mathrm{Scm}^{-1}$ doped with $\mathrm{I}_{2}$. 


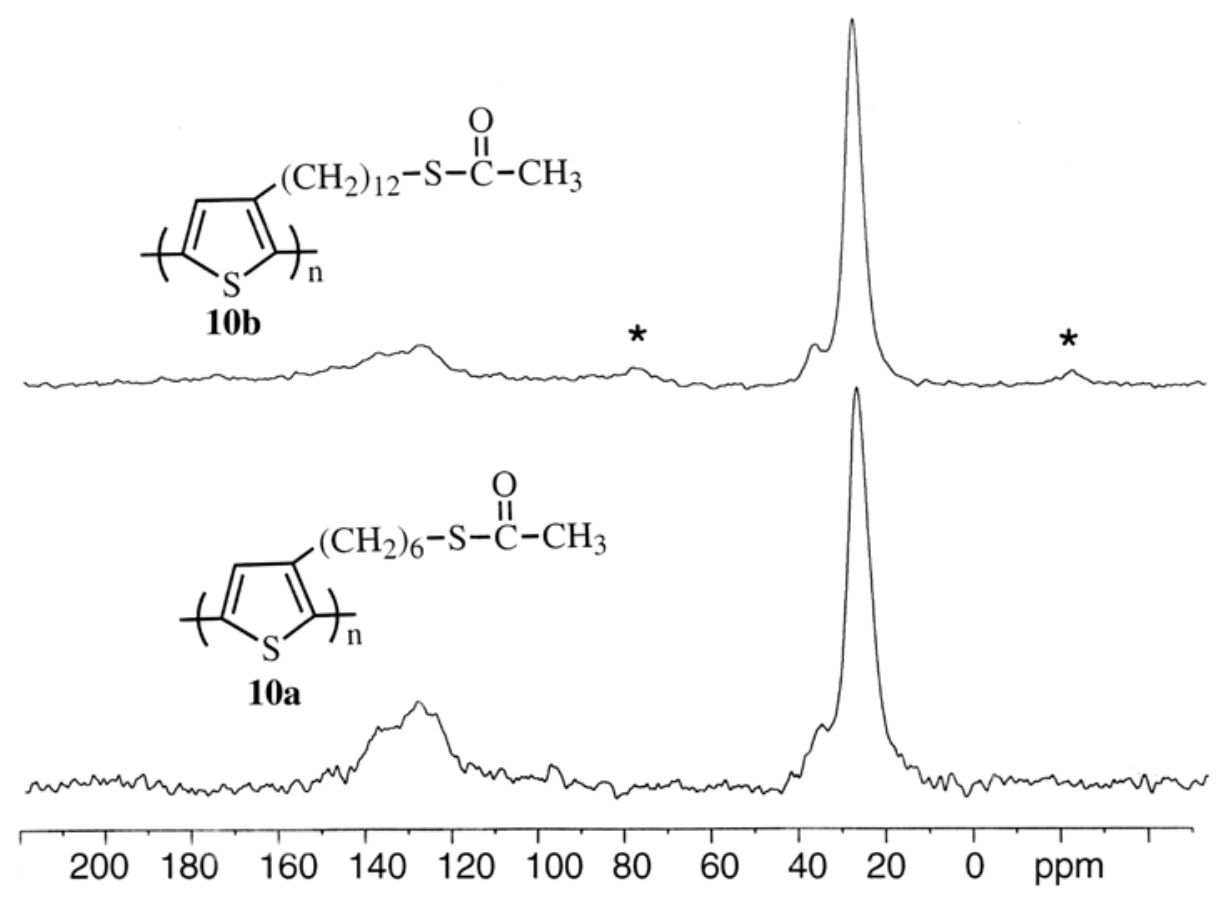

Figure 2. ${ }^{13} \mathrm{C}$ CP-MAS NMR spectra of $\mathbf{1 0 a}$ and $\mathbf{1 0 b}$. The peaks marked with * are spinning sidebands.

Since we also wanted the thiol containing polymer we attempted to convert the thioacetate polymer 10a to the thiol 11 by several different reactions. Stirring with $\mathrm{KOH} / \mathrm{EtOH}$ for 13 hours under argon at room temperature, refluxing with $\mathrm{KOH} / \mathrm{H}_{2} \mathrm{O} / \mathrm{CH}_{2} \mathrm{Cl}_{2}$ for 32 hours under argon, refluxing with $\mathrm{KOH} / \mathrm{H}_{2} \mathrm{O} / \mathrm{CH}_{2} \mathrm{Cl}_{2} / \mathrm{NaBH}_{4}$ for 48 hours under argon and stirring with $\mathrm{KOH} / \mathrm{EtOH} / \mathrm{NaBH}_{4}$ under argon at room temperature all failed to give any thiol product. The IR spectrum of the product was identical to that of the reactant in all cases. The lack of reaction is no doubt due to the insolubility of the polymer.

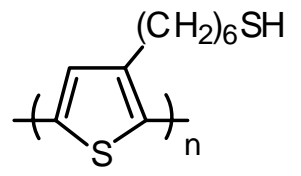

11

The next approach to poly[3-(6-mercaptohexyl)thiophene] (11) involved post-polymerization substitution of bromo-polymer 1. A standard method for preparing thiols from a halide is by $\mathrm{S}_{\mathrm{N} 2}$ reaction with thiourea to produce an isothiouronium salt, which, in turn, can be hydrolyzed with aqueous $\mathrm{Na}_{2} \mathrm{CO}_{3}{ }^{21,22}$ to produce a thiol. ${ }^{23}$ Scheme 3 shows this sequence of reactions as applied to polymer 1. Polymer 11 was produced as a red powder which was insoluble in standard organic solvents 


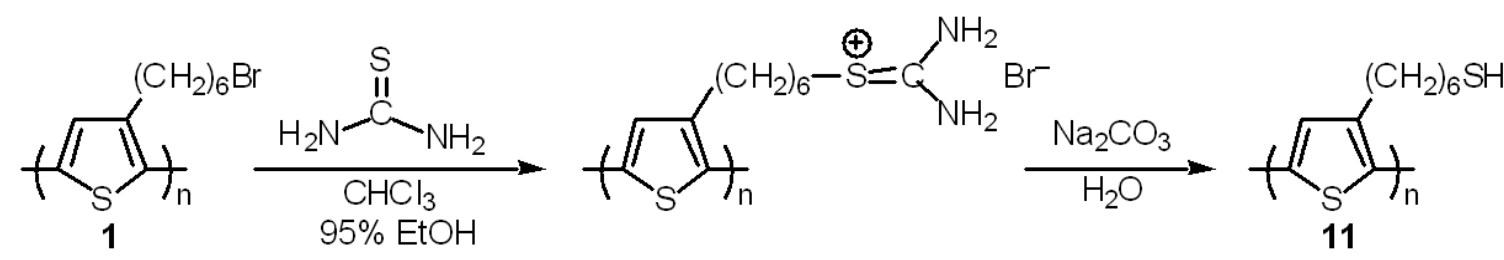

\section{Scheme 3}

such as $\mathrm{CHCl}_{3}, \mathrm{THF}, \mathrm{DMF}$, DMSO, toluene, xylene and o-dichlorobenzene but was very slightly soluble in refluxing thiophene.

Zhai, et al. ${ }^{8}$ report that the HT-regioregular version of $\mathbf{1 1}$ is soluble in common organic solvents. Once again, the lack of solubility may be the result of the $\mathbf{1 1}$ which we have prepared from 1 being about twice the molecular weight of the HT-regioregular 11 prepared by Zhai, et al. Our structure proof rests on the IR and 13C CP-MAS spectra as well as elemental analysis. The thiophene and aliphatic $\mathrm{C}-\mathrm{H}$ stretching frequencies were at 3059, 2853 and $2927 \mathrm{~cm}^{-1}$. Unfortunately there was not an obvious S-H stretching band in the range $2550-2600 \mathrm{~cm}^{-1}$ but because it is characteristically rather weak it may go undetected in thin films or in dilute solutions. ${ }^{24}$ The ${ }^{13} \mathrm{C}$ CP-MAS spectrum of 11 is shown in Figure 3. The integrated ratio of the aromatic peaks (at $\delta \approx 120-145$ ) to aliphatic peaks (at $\delta \approx 20-45$ ) is 0.58 (including spinning sidebands): 1.00 whereas the required ratio for 11 is $0.67: 1.00$. The pressed pellet conductivities for polymer 11 were $\sigma=2.3 \times 10^{-2} \mathrm{Scm}^{-1}$ doped with $\mathrm{FeCl}_{3}$ and $\sigma=0.44 \mathrm{Scm}^{-1}$ doped with $\mathrm{I}_{2}$.

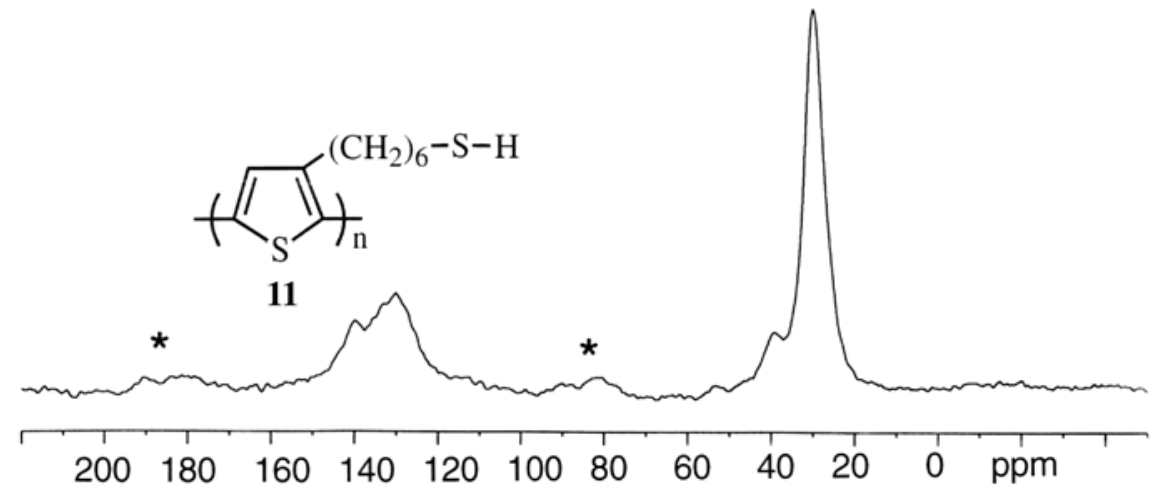

Figure 3. ${ }^{13} \mathrm{C}$ CP-MAS NMR spectrum of 11. The peaks marked with * are spinning sidebands.

\section{Thermogravimetric analysis}

Thermogravimetric analyses (TGA) were run on polymers $\mathbf{1 , ~ 8}$, and $\mathbf{1 1}$ to examine their thermal stabilities. All three showed two stage weight losses (Figure 4). For 1, decomposition began at about $330{ }^{\circ} \mathrm{C}$, and the second step began at about $470{ }^{\circ} \mathrm{C}$ and ended at about $580{ }^{\circ} \mathrm{C}$. For 8 , which was less stable than 1 , decomposition began slowly at about $150{ }^{\circ} \mathrm{C}$ and the second step began at about $370{ }^{\circ} \mathrm{C}$ and ended at about $510^{\circ} \mathrm{C}$. For 11 , decomposition began at about $210{ }^{\circ} \mathrm{C}$ 
and the second step began at about $360{ }^{\circ} \mathrm{C}$ and ended at about $520^{\circ} \mathrm{C}$ which makes this polymer of intermediate stability. From the weight loss it appears that the first step in each case is loss of $\mathrm{HBr}, \mathrm{HI}$ and $\mathrm{H}_{2} \mathrm{~S}$ respectively. For polymer 1 the first weight loss is about $36 \%$ and loss of $\mathrm{HBr}$ requires 33\%, for polymer 8 the first weight loss is about $41-45 \%$ and loss of HI requires $44 \%$ while for polymer 11 the first weight loss is about $26 \%$ and loss of $\mathrm{H}_{2} \mathrm{~S}$ requires $17 \%$. The second weight loss is most likely due to side chain loss.
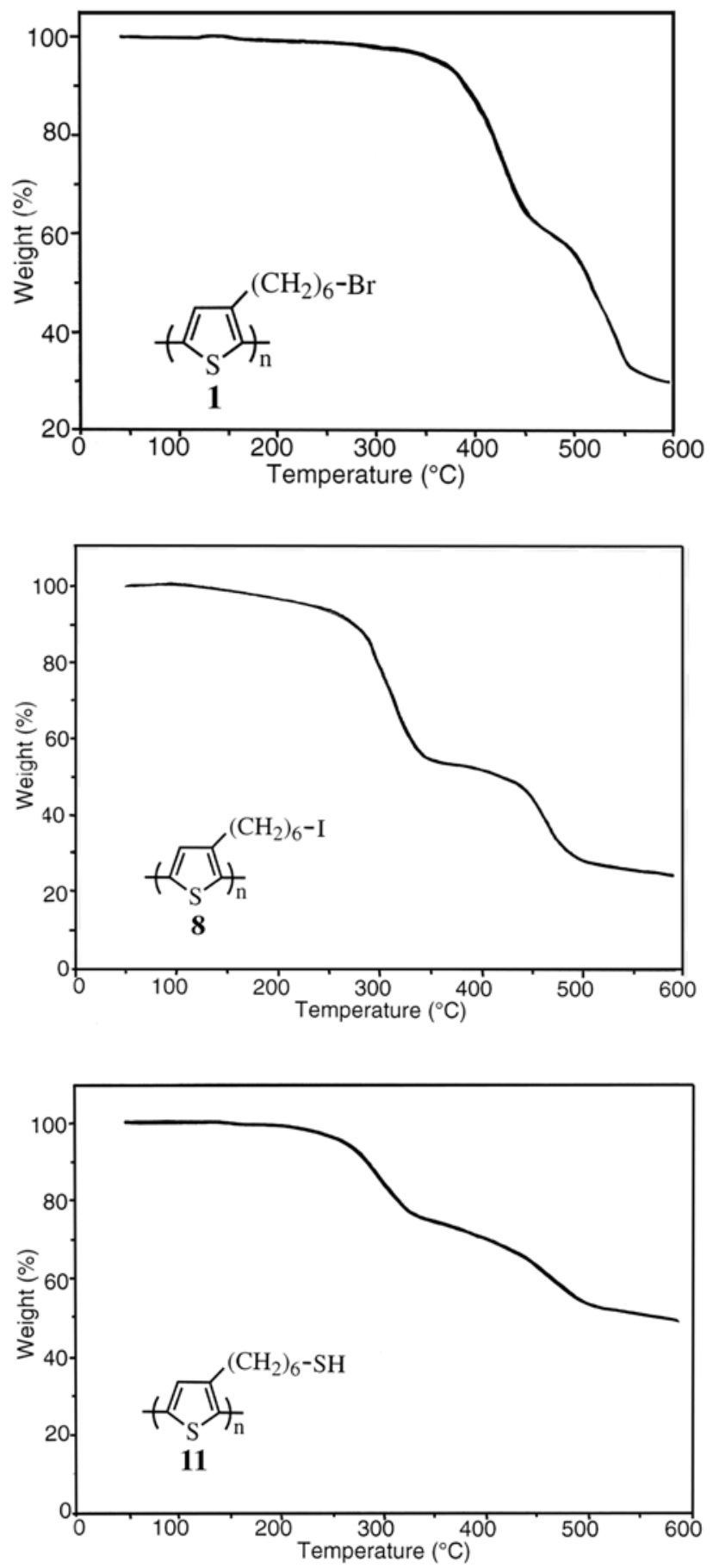
Figure 4. TGA curves of polymers 1, 8 and 11.

\section{Experimental Section}

General Procedures. ${ }^{1} \mathrm{H}$ and ${ }^{13} \mathrm{C}$ NMR spectra were obtained on either a Bruker MSL 300 spectrometer operating at $300.13 \mathrm{MHz}$ for ${ }^{1} \mathrm{H}$ and $75.97 \mathrm{MHz}$ for ${ }^{13} \mathrm{C}$ or on a JEOL Eclipse 500 spectrometer operating at $500.16 \mathrm{MHz}$ for ${ }^{1} \mathrm{H}$ and $125.78 \mathrm{MHz}$ for ${ }^{13} \mathrm{C}$. $\mathrm{CDCl}_{3}$ was used as the solvent with TMS $(\delta=0.00 \mathrm{ppm})$ and $\mathrm{CDCl}_{3}(\delta=77.0 \mathrm{ppm})$ used as internal reference for ${ }^{1} \mathrm{H}$ and ${ }^{13} \mathrm{C}$ spectra, respectively. CP-MAS ${ }^{13} \mathrm{C}$ NMR spectra were taken on a Bruker Avance 400 instrument operating at $100.63 \mathrm{MHz}$ by Bruker Instruments, Billerica, MA. FT-IR spectra were obtained on a Biorad-Digilab FTS-40 or a Bruker VECTOR22 FT-IR instrument using powdered samples (approximately 1-2 weight \%) with $\mathrm{KBr}$ in a diffuse reflectance unit or liquid samples between $\mathrm{NaCl}$ plates. Gel permeation chromatography (GPC) was carried out on a Waters GPC system, using a Waters Model 510 HPLC pump, a Model 490 multiwavelength detector $\lambda=254$ $\mathrm{nm}$ ), Millennium 2010 Software, a serial combination of 103, 104, and $105 \AA$ Ultrastyragel columns and THF with a flow rate of $1.0 \mathrm{~mL} / \mathrm{min}$. The calibration curve was established by use of polystyrene standards with a molecular weight range of 800 to 9x105 g/mol. HPLC was performed on a Waters HPLC system, using a Waters Model 501 HPLC pump, a Lambda-Max Model 481 LC UV-vis detector (254 nm), Maxima 820 Chromatography Software, and an Econosil C18 10U $(10 \mu \mathrm{m})$ reverse phase column $(250 \mathrm{~mm} \times 4.6 \mathrm{~mm})$. Methanol was used as the eluent with a flow rate of $1.0 \mathrm{~mL} / \mathrm{min}$. UV-vis-NIR spectra were recorded on a Cary $5 \mathrm{E}$ UV-visNIR spectrophotometer using tetrahydrofuran solutions and polymer thin films cast onto quartz cuvettes from polymer-THF solutions. Fluorescence spectra were measured on a Perkin-Elmer Model 204 fluorescence spectrophotometer using a Perkin-Elmer 150 Xenon power supply. Samples were either polymer-THF solutions or polymer thin films on glass substrates. TGA was carried out on a DuPont model 9900 Thermal Analysis system fitted with a Model 951 Thermogravimetric Analyzer, under nitrogen with a heating rate of $10{ }^{\circ} \mathrm{C} / \mathrm{min}$. Elemental analyses were obtained either on a Perkin-Elmer $2400 \mathrm{CHN}$ analyzer or determined by Texas Analytical Laboratories, Stafford, Texas. Melting points were determined using a ThomasHoover capillary melting point apparatus and are uncorrected. EI mass spectra were obtained at $70 \mathrm{eV}$ on a Finnigan MAT TSQ-70 instrument. The electrical conductivity of doped polymer films was measured using the standard four-in-line probe method. ${ }^{25,26}$ The thickness of polymer films was determined with an Alpha-Step 200 profilometer or Mitutoyo Digimatic Digital Micrometer.

12-Bromododecan-1-ol. ${ }^{10}$ 12-Bromododecan-1-ol was prepared essentially according to the literature procedure. ${ }^{10} 20.2 \mathrm{~g}(0.100 \mathrm{~mol})$ of 1,12-dodecanediol, $100 \mathrm{~mL}$ of heptane and $40 \mathrm{~mL}$ of $48 \%$ aq. $\mathrm{HBr}$ were put into a $250 \mathrm{~mL} 3$-necked flask equipped with a magnetic stirrer. The 
mixture was stirred under reflux for $25 \mathrm{~h}$ and the organic layer was extracted with ethyl ether $(3 \times 100 \mathrm{~mL})$. The combined organic extract was washed with deionized water $(3 \times 100 \mathrm{~mL})$, followed by $5 \% \mathrm{Na}_{2} \mathrm{CO}_{3}$ solution $(2 \times 100 \mathrm{~mL})$ and $150 \mathrm{~mL}$ of saturated $\mathrm{NaCl}$ solution, dried $\left(\mathrm{MgSO}_{4}\right)$ and the solvent was removed in vacuum. The crude product was purified by silica gel flash column chromatography using hexane/ethyl acetate $(5: 1 \mathrm{v} / \mathrm{v})$ as eluent. $16.0 \mathrm{~g}$ of the 12 bromododecane-1-ol was obtained as white crystals $\left(60 \%\right.$ yield). mp 31.5-32.5 ${ }^{\circ} \mathrm{C}$ (Lit. ${ }^{27} 31$ $\left.32{ }^{\circ} \mathrm{C}\right){ }^{1} \mathrm{H}$ NMR $\delta: 1.20-1.50(\mathrm{~m}, 17 \mathrm{H}$ ), 1.57 (quintet, $2 \mathrm{H}, J=7 \mathrm{~Hz}$ ), 1.85 (quintet, $2 \mathrm{H}, J=7$ $\mathrm{Hz}), 3.40$ (t, $2 \mathrm{H}, J=7 \mathrm{~Hz}), 3.64$ (t, 2H, $J=7 \mathrm{~Hz})$.

1-Bromo-6-(2-tetrahydropyranyloxy)hexane (5a). ${ }^{11}$ In a modification of the literature procedure $^{11}$ a solution of 6-bromohexane-1-ol (18.1 g, $\left.0.100 \mathrm{~mol}\right)$ and 3,4-dihydro-2H-pyran $(11.0 \mathrm{~g}, 0.130 \mathrm{~mol})$ in $60 \mathrm{~mL}$ of hexane was slowly added to a suspension of Amberlyst $\mathrm{H}-15$ (1.00 g, 20-60 mesh) in $20 \mathrm{~mL}$ of hexane. The mixture was stirred at $0{ }^{\circ} \mathrm{C}$ for $3 \mathrm{~h}$, and an additional $1.5 \mathrm{~h}$ at room temperature. The resin was filtered and the solvent was removed in vacuo. The residue was purified by silica gel flash column chromatography eluting with hexane/ethyl acetate (10:1.4 v/v). $22.0 \mathrm{~g}(90 \%)$ of $\mathbf{5 a}$ was obtained as a clear, colorless liquid. ${ }^{1} \mathrm{H}$ NMR $\delta: 1.35-1.90$ (m, 14 H), 3.32-3.39 (m, 3 H), 3.42-3.51 (m, 1 H), 3.66-3.73 (m, $1 \mathrm{H}), 3.80-$ $3.88(\mathrm{~m}, 1 \mathrm{H}), 4.56(\mathrm{dd}, 1 \mathrm{H}) ;{ }^{13} \mathrm{C} \mathrm{NMR} \delta: 67.4,62.4,33.9,32.8,30.8,29.6,28.1,25.5_{6}, 25.5_{4}$, 19.6. IR (neat, $\mathrm{cm}^{-1}$ ) 2939, 2864, 1440, 1351, 1261, 1201, 1134, 1077, 1032, 987, 905, 869, 814, 729, 645, 563. Anal. Calcd. for $\mathrm{C}_{11} \mathrm{H}_{21} \mathrm{O}_{2} \mathrm{Br}$ : C, 49.82; H, 7.98. Found: C, 50.19; H, 7.78. MS [m/z (\% rel. int.)]: 266.1 (11, M+3), 265.1 (90, M+2), $264.1(10, \mathrm{M}+1), 263.1$ (88, M+), 193.1 (23), 191.1 (23), 165.1 (58), 163.1 (70), 123.0 (26), 121.0 (28), 115.2 (82), 101.1 (100).

1-Bromo-12-(2-tetrahydropyranyloxy)dodecane (5b). ${ }^{10} 4.70 \mathrm{~g}$ of 12-bromo-1-dodecanol was used employing the literature procedure. ${ }^{10}$ The crude product was purified by silica gel flash column chromatography, eluting with hexane/ethyl acetate $(25: 1 \mathrm{v} / \mathrm{v})$, to give $6.00 \mathrm{~g}(97 \%)$ of $\mathbf{5 b}$ as a colorless liquid. ${ }^{1} \mathrm{H}$ NMR $\delta$ : $1.20-1.59(\mathrm{~m}, 22 \mathrm{H}), 1.62-1.88(\mathrm{~m}, 4 \mathrm{H}), 3.30-3.40(\mathrm{~m}, 3 \mathrm{H})$, 3.44-3.52 (m, $1 \mathrm{H}), 3.70(\mathrm{dt}, 1 \mathrm{H}), 3.81-3.90(\mathrm{~m}, 1 \mathrm{H}), 4.55(\mathrm{t}, 1 \mathrm{H}) ;{ }^{13} \mathrm{C}$ NMR $\delta: 98.8,67.6,62.2$, 33.9 , 32.8, 30.7, 29.7, 29.5 , 29.49, 29.46, 29.4, 29.37 , 28.7, 28.1, 26.2, 25.5, 19.6. Anal. Calcd. for $\mathrm{C}_{17} \mathrm{H}_{23} \mathrm{O}_{2} \mathrm{Br}$ : C, 58.45; $\mathrm{H}, 9.52$. Found: C, 58.46; H, 9.46.

3-[6-(2-Tetrahydropyranyloxy)hexyl]thiophene (6a). ${ }^{28}$ Into a $100 \mathrm{~mL}$, three-necked flask equipped with a magnetic stirrer, a pressure-equalizing dropping funnel, and a reflux condenser attached to an argon gas inlet was put $0.85 \mathrm{~g}$ (35 mg-atom) of magnesium turnings. A solution of $1.00 \mathrm{~g}$ of 1-bromo-6-(2-tetrahydropyranyloxy)hexane $(\mathbf{5 a} ; 3.80 \mathrm{mmol})$ in $20 \mathrm{~mL}$ of dry THF was added rapidly and an exothermic reaction occurred. Then an additional $7.08 \mathrm{~g}$ (total $=8.08 \mathrm{~g}$; $30.0 \mathrm{mmol}$ ) of $\mathbf{5 a}$ in $50 \mathrm{~mL}$ of dry THF was added over ca. $1.5 \mathrm{~h}$ at room temperature. The mixture was stirred at room temperature for $2 \mathrm{~h}$, then heated at about $45{ }^{\circ} \mathrm{C}$ with stirring for $1 \mathrm{~h}$. Then, into a $100 \mathrm{~mL}$ three-necked flask, equipped in the same manner as above, was put $4.20 \mathrm{~g}$ (26.0 mmol) of 3-bromothiophene, $20 \mathrm{~mL}$ of dry ether and $20 \mathrm{mg}$ of $\mathrm{Ni}(\mathrm{dppp}) \mathrm{Cl}_{2}$ $\left[\mathrm{Ni}\left(\mathrm{Ph}_{2} \mathrm{P}\left(\mathrm{CH}_{2}\right)_{3} \mathrm{PPh}_{2} \mathrm{Cl}_{2}\right]\right.$. The Grignard reagent prepared above was transferred to a dropping funnel and added over $2 \mathrm{~h}$ with stirring to the mixture cooled in an ice bath. After the addition was complete, stirring was continued for an additional $3 \mathrm{~h}$ at the ice bath temperature. A white 
precipitate formed and the resulting mixture was allowed to warm to room temperature. Stirring was continued for another $18 \mathrm{~h}$ and then the mixture was heated with stirring at $50{ }^{\circ} \mathrm{C}$ for $1 \mathrm{~h}$. The mixture was cooled to room temperature and poured into $100 \mathrm{~mL}$ of $1 \mathrm{M} \mathrm{NaOH}$ solution. This was extracted with diethyl ether $(2 \times 50 \mathrm{~mL})$ and the combined ether extracts were washed with water $(4 \times 60 \mathrm{~mL})$ and dried $\left(\mathrm{MgSO}_{4}\right)$. After filtration, the ether was removed in vacuum to give a crude brown product which was purified by silica gel flash column chromatography using hexane/ethyl acetate $(33: 1 \mathrm{v} / \mathrm{v})$ as eluent. $4.80 \mathrm{~g}(70 \%)$ of $6 \mathbf{a}$ was obtained as a clear, colorless liquid with a purity $>98 \%$ (HPLC area percent, $t_{R}=4.22 \mathrm{~min}$.). ${ }^{1} \mathrm{H}$ NMR $\delta: 1.30-1.85(\mathrm{~m}, 14 \mathrm{H})$, 2.61 (t, $2 \mathrm{H}, J=7 \mathrm{~Hz}), 3.30-3.60$ (m, $2 \mathrm{H}), 3.65-3.90$ (m, $2 \mathrm{H}), 4.56$ (br, m, $1 \mathrm{H}), 6.84-6.95$ (m, 2 $\mathrm{H}), 7.10-7.24(\mathrm{~m}, 1 \mathrm{H}) .{ }^{13} \mathrm{C}$ NMR $\delta: 19.6,25.4,26.0,29.1,29.6,30.1,30.4,30.7,62.2$, 67.5, 98.8, 119.8, 125.1, 128.3, 143.1. IR (neat, $\mathrm{cm}^{-1}$ ): 3101, 3050, 2935, 2857, 1537, 1454, 1440, $1352,1260,1200,1136,1120,1077,1033,868,814,773,684$, 633. Anal. Calcd. for $\mathrm{C}_{15} \mathrm{H}_{24} \mathrm{O}_{2} \mathrm{~S}$ : C, 67.12; H, 9.01. Found: C, 67.48; H, 9.07.

3-[12-(2-Tetrahydropyranyloxy)dodecyl]thiophene (6b). ${ }^{28}$ was made in the same way as $6 \mathbf{a}$. The crude product was purified by silica gel flash column chromatography using hexane/ethyl acetate $(50: 1 \mathrm{v} / \mathrm{v})$ as eluent to give $35-39 \%$ of the colorless liquid product with a purity $>98 \%$ (HPLC area percent, $t_{R}=7.53 \mathrm{~min}$.). The product became solid on standing a few $\mathrm{h}$ at room temperature. mp: $29.0-34.0{ }^{\circ} \mathrm{C} .{ }^{1} \mathrm{H}$ NMR $\delta: 1.26-1.80(\mathrm{~m}, 26 \mathrm{H}), 2.61(\mathrm{t}, 2 \mathrm{H}, J=8 \mathrm{~Hz}), 3.30-$ 3.55 (m, 2 H), 3.68-3.90 (m, 2 H), 4.57 (t, $1 \mathrm{H}, J=8 \mathrm{~Hz}), 6.85-6.94$ (m, $2 \mathrm{H}), 7.12-7.22(\mathrm{~m}, 1$ H). ${ }^{13} \mathrm{C}$ NMR $\delta: 19.7,25.5,26.3,29.4,29.5,29.5,29.6$ (br), 29.6, 29.8, 30.3, 30.5, 30.8, 62.3, 67.7, 98.8, 119.7, 125.0, 128.3, 143.2. IR (KBr, $\left.\mathrm{cm}^{-1}\right): 3102,3050,2925,2853,1537,1465$, 1440, 1352, 1323, 1260, 1200, 1136, 1121, 1078, 1034, 986, 905, 898, 834, 815, 771, 723, 683. Anal. Calcd. for $\mathrm{C}_{21} \mathrm{H}_{36} \mathrm{O}_{2} \mathrm{~S}$ : C, 71.54; $\mathrm{H}, 10.29$. Found: $\mathrm{C}, 71.88 ; \mathrm{H}, 10.60$.

6-(3-Thienyl)-1-hexanol (7a). ${ }^{28}$ A solution of $6 \mathbf{a}(1.08 \mathrm{~g}, 4.00 \mathrm{mmol})$ in methanol $(20 \mathrm{~mL})$ was added to Amberlyst H-15 (0.20 g, 20-60 mesh) in $10 \mathrm{~mL}$ of methanol, the mixture was stirred for $4 \mathrm{~h}$ at room temperature and then heated at $45{ }^{\circ} \mathrm{C}$ for $1 \mathrm{~h}$. The resin was filtered and the solvent was removed in vacuum. Silica gel column chromatography using hexane/ethyl acetate (10:3 $\mathrm{v} / \mathrm{v})$ as eluent gave $0.76 \mathrm{~g}(98 \%)$ of $7 \mathbf{a}$ as a clear colorless liquid with a purity $>99 \%$ (HPLC, $t_{R}=$ $3.3 \mathrm{~min})$. UV-vis (hexane): $\lambda_{\max } 235 \mathrm{~nm}\left(\mathrm{e}=4.58 \times 10^{3}\right)$. ${ }^{1} \mathrm{H}$ NMR $\delta: 1.30-1.40(\mathrm{~m}, 4 \mathrm{H}), 1.45-$ $1.68(\mathrm{~m}, 4 \mathrm{H}), 2.59(\mathrm{t}, 2 \mathrm{H}, J=8 \mathrm{~Hz}), 3.25(\mathrm{~s}, 1 \mathrm{H}), 3.54(\mathrm{t}, 2 \mathrm{H}, J=7 \mathrm{~Hz}), 6.84-6.92(\mathrm{~m}, 2 \mathrm{H})$, 7.10-7.24 (m, $1 \mathrm{H}) .{ }^{13} \mathrm{C}$ NMR $\delta: 25.4,28.9,30.0,30.3,32.4,62.4,119.6,124.9,128.0,142.8$. IR (neat, $\mathrm{cm}^{-1}$ ): 3333, 3104, 3077, 2931, 2857, 1537, 1459, 1439, 1411, 1239, 1074, 1155, 1055, 1033, 966, 911, 856, 834, 773, 684, 633. Anal. Calcd. for $\mathrm{C}_{10} \mathrm{H}_{16} \mathrm{OS}$ : C, 65.17; H, 8.75. Found: C, 65.11; H, 8.47.

12-(3-Thienyl)-1-dodecanol (7b). ${ }^{28}$ was made in the same manner as 6-(3-thienyl)-1-hexanol (7a). The product was obtained as white crystals with purity $>98 \%$ (HPLC, $t_{R}=4.26 \mathrm{~min}$.). Yield: $89 \%$. mp: $47.5-48.5^{\circ} \mathrm{C}$. UV-vis (hexane): $\lambda_{\max } 235 \mathrm{~nm}(\varepsilon=4.47 \times 103) .{ }^{1} \mathrm{H}$ NMR $\delta: 1.21-$ $1.44(\mathrm{~m}, 17 \mathrm{H}), 1.50-1.70(\mathrm{~m}, 4 \mathrm{H}), 2.62(\mathrm{t}, 2 \mathrm{H}, J=8 \mathrm{~Hz}), 3.64$ (t, $2 \mathrm{H}, J=7 \mathrm{~Hz}), 6.90-6.95(\mathrm{~m}$, $2 \mathrm{H}), 7.20-7.25$ (m, 1 H). ${ }^{13} \mathrm{C}$ NMR $\delta: 25.7,29.3,29.4,29.6$ (br), 30.3, 30.6, 32.8, 63.1, 119.7, 125.0, 128.3, 143.3. IR (neat, $\mathrm{cm}^{-1}$ ): 3426, 3365, 3099, 3053, 2923, 2850, 1564, 1559, 1462, 
1438, 1365, 1344, 1300, 1155, 1079, 1063, 1003, 975, 864, 833, 770, 756, 726, 683, 622, 582. Anal. Calcd. for $\mathrm{C}_{16} \mathrm{H}_{28} \mathrm{OS}$ : C, 71.59; H, 10.51. Found: C, 71.47; H, 10.37.

6-(3-Thienyl)-1-bromohexane (3). ${ }^{9}$ In a $50 \mathrm{~mL}$ three-necked flask fitted with a pressure equalizing dropping funnel, and a condenser capped with a drying tube was placed $0.540 \mathrm{~g}(2.00$ $\mathrm{mmol}$ ) of $\mathrm{PBr}_{3}$ and $20 \mathrm{~mL}$ of freshly distilled benzene. A mixture of $0.10 \mathrm{~mL}$ of dry pyridine and $2 \mathrm{~mL}$ of the benzene was added dropwise via syringe with stirring over a period of 10 minutes. The flask was then placed in an ice-salt bath, and the contents cooled to $-10{ }^{\circ} \mathrm{C}$. A mixture of $1.00 \mathrm{~g}$ of $7 \mathrm{a}(5.43 \mathrm{mmol})$ and pyridine $(0.10 \mathrm{~mL})$ in $5 \mathrm{~mL}$ of benzene was added slowly over a period of $1 \mathrm{~h}$ keeping the temperature between $-10^{\circ} \mathrm{C}$ and $-5^{\circ} \mathrm{C}$. Stirring was continued for 1 additional $\mathrm{h}$ in the cooling bath and then the mixture was allowed to warm to room temperature and stirred for $46 \mathrm{~h}$. The mixture was poured into $100 \mathrm{~mL}$ of saturated $\mathrm{NaHCO}_{3}$ solution and two small portions of benzene were used to rinse the flask $(2 \times 20 \mathrm{~mL})$. The combined extracts were washed with water $(4 \times 60 \mathrm{~mL})$ and dried $\left(\mathrm{MgSO}_{4}\right)$. After filtration, the benzene was removed in vacuum giving a crude product which was purified by silica gel column chromatography, eluting with hexane/ethyl acetate $(10: 1 \mathrm{v} / \mathrm{v})$. The yield of 3 was $0.66 \mathrm{~g}\left(49 \%\right.$; HPLC purity $>99 \%, t_{R}=$ $4.17 \mathrm{~min})$. UV-vis (hexane): $\lambda_{\max } 234 \mathrm{~nm}\left(\mathrm{e}=6.98 \times 10^{3}\right) .{ }^{1} \mathrm{H}$ NMR $\delta: 1.28-1.48(\mathrm{~m}, 4 \mathrm{H}), 1.61$ (quintet, $2 \mathrm{H}$ ), 1.82 (quintet, $2 \mathrm{H}), 2.60$ (t, $2 \mathrm{H}, J=8 \mathrm{~Hz}$ ), 3.35 (t, $2 \mathrm{H}, J=7 \mathrm{~Hz}), 6.86-6.92$ (m, 2 $\mathrm{H}), 7.10-7.24$ (m, $1 \mathrm{H}) .{ }^{13} \mathrm{C}$ NMR $\delta: 27.9,28.3,30.1,30.3,32.7,33.9,119.9,125.1,128.2,142.8$. IR (neat, $\mathrm{cm}^{-1}$ ): 3103, 3050, 3004, 2931, 2855, 1537, 1460, 1438, 1410, 1258, 1238, 1153, 1080, 860, 834, 773, 685, 635, 561. Anal. Calcd. for $\mathrm{C}_{10} \mathrm{H}_{15} \mathrm{BrS}$ : C, 48.59; H, 6.12. Found: C, 48.74; H, 6.33 .

12-(3-Thienyl)-1-bromododecane (4). In a $100 \mathrm{~mL}$ three-necked flask fitted with a pressure equalizing dropping funnel, and a condenser capped with a drying tube was placed $0.490 \mathrm{~g}(1.80$ $\mathrm{mmol}$ ) of $\mathrm{PBr}_{3}$ and $20 \mathrm{~mL}$ of freshly distilled benzene. A mixture of $0.10 \mathrm{~mL}$ of dry pyridine and $2 \mathrm{~mL}$ of benzene was added dropwise via syringe with stirring over a period of 10 minutes. The flask was placed in an ice-salt bath, the contents were cooled to $-10^{\circ} \mathrm{C}$ and a mixture of $1.32 \mathrm{~g}$ of $7 \mathbf{b}(4.92 \mathrm{mmol})$ and pyridine $(0.10 \mathrm{~mL})$ in $5 \mathrm{~mL}$ of benzene was added slowly over a period of $1 \mathrm{~h}$ keeping the temperature between $-10{ }^{\circ} \mathrm{C}$ and $-5{ }^{\circ} \mathrm{C}$. Stirring was continued for 1 additional $\mathrm{h}$ in the cooling bath and then the mixture was allowed to warm to room temperature and stirred for $46 \mathrm{~h}$. The product was purified by silica gel flash column chromatography using hexane/ethyl acetate $(100: 1 \mathrm{v} / \mathrm{v})$ as eluent to give $0.47 \mathrm{~g}(29 \%)$ of the colorless liquid product $4.48 \% \mathrm{HBr}$ was also used in place of $\mathrm{PBr}_{3}$ with benzene as solvent. The reaction was carried out for $6 \mathrm{~h}$ under reflux. $1.50 \mathrm{~g}$ of $7 \mathbf{b}, 13 \mathrm{~mL}$ of $48 \% \mathrm{HBr}$, and $15 \mathrm{~mL}$ of benzene were placed in a $100 \mathrm{~mL}$ round bottomed flask under argon. The reaction was run for $6 \mathrm{~h}$ under reflux and gave 37\% $(0.66 \mathrm{~g})$ of 4. The chief advantages of this latter method for preparing 4 were that not only did it give improved yields (to $37-46 \%$ ) but also that $35-47 \%$ of unreacted $7 \mathbf{b}$ could be completely recovered from the reaction mixture for reuse. UV-vis (hexane): $\lambda_{\max } 235 \mathrm{~nm}\left(\varepsilon=4.71 \times 10^{3}\right) .{ }^{1} \mathrm{H}$ NMRi $\delta$ : 1.25-1.50 (m, $16 \mathrm{H}$ ), 1.51-1.70 (quintet, $2 \mathrm{H}$ ), 1.83 (quintet, $2 \mathrm{H}, J=7 \mathrm{~Hz}), 2.61(\mathrm{t}, 2 \mathrm{H}$, $J=8 \mathrm{~Hz}), 3.38$ (t, $2 \mathrm{H}, J=7 \mathrm{~Hz}), 6.86-7.00(\mathrm{~m}, 2 \mathrm{H}), 7.10-7.23(\mathrm{~m}, 1 \mathrm{H}) .{ }^{13} \mathrm{C}$ NMR $\delta: 28.1,28.7$, 29.3, 29.4, 29.5 (br), 30.2, 30.5, 32.8, 33.9, 119.7, 124.9, 128.2, 143.1. IR (neat, $\mathrm{cm}^{-1}$ ): 3104, 
3050, 2926, 2853, 1536, 1463, 1439, 1409, 1387, 1247, 1079, 857, 834, 772, 722, 683, 636. Anal. Calcd. for $\mathrm{C}_{16} \mathrm{H}_{27} \mathrm{BrS}$ : C, 58.00; H, 8.21. Found: C, 58.07; H, 8.25.

Poly[3-(6-bromohexyl)thiophene] (1). 6-(3-Thienyl)-1-bromohexane (3) 0.350g (1.42 mmol) in $5 \mathrm{~mL}$ of freshly distilled $\mathrm{CHCl}_{3}$ was added to a stirred solution of $0.920 \mathrm{~g}$ of anhydrous $\mathrm{FeCl}_{3}$ $(5.68 \mathrm{mmol})$ in $30 \mathrm{~mL}$ of freshly distilled $\mathrm{CHCl}_{3}$. The reaction vessel was purged with nitrogen and stirred for $2 \mathrm{~h}$ at room temperature. The black precipitate which formed was filtered, washed with methanol and then added to $200 \mathrm{~mL}$ of $\mathrm{CHCl}_{3}$ and $10 \mathrm{~mL}$ of conc. aqueous ammonia and stirred for $15 \mathrm{~min}$. at room temperature. Some insoluble red-orange material was filtered. The $\mathrm{CHCl}_{3}$ solution was washed several times with water and dried $\left(\mathrm{MgSO}_{4}\right)$. The solvent was removed in vacuo to give dark red $\mathbf{1}$. Low molecular weight products were removed by adding a concentrated $\mathrm{CHCl}_{3}$ solution of 1 into $50 \mathrm{~mL}$ of methanol. The product then was filtered and dried under vacuum at room temperature for $12 \mathrm{~h}$ to give $0.215 \mathrm{~g}(61 \%)$ of $1 .{ }^{1} \mathrm{H}$ NMR $\delta: 6.99$ (br m, 1 H), 3.43 (br t, 2 H), 2.82 and 2.60 (br m, 2 H), 1.90-1.20 (br m, 8 H), 0.90-0.85 (br, small peaks, about 3-5\%). ${ }^{13} \mathrm{C}$ NMR $\delta$ : 139.6, 133.7, 130.6, 128.7, 33.9, 32.7, 30.3, 29.3, 28.6, 28.0. IR (KBr, $\left.\mathrm{cm}^{-1}\right): 3054,2929,2854,1647,1509,1458,1437,1258,1235,1103,830,726$, $669,645,561$. UV-vis (THF) $\lambda_{\max } 436 \mathrm{~nm}$, band edge $520 \mathrm{~nm}(2.39 \mathrm{eV}$ ); Film (cast from THF) $\lambda_{\max } 492 \mathrm{~nm}$, band edge $630 \mathrm{~nm}(1.97 \mathrm{eV})$. Fluorescence: THF solution $\lambda_{\text {Emission max }}=573 \mathrm{~nm}$ and film (cast from THF) $\lambda_{\text {Emission max }}=670 \mathrm{~nm}$ at excitation wavelengths of $506 \mathrm{~nm}$ and $400 \mathrm{~nm}$, respectively. GPC analysis: $\overline{\mathrm{M}}_{\mathrm{n}}=51,500(\mathrm{PDI}=5.2)$. Anal. Calcd. for $\left(\mathrm{C}_{10} \mathrm{H}_{13} \mathrm{SBr}\right)_{\mathrm{n}}$ : $\mathrm{C}, 48.99$; H, 5.34; Br, 32.59. Found: C, 48.87; H, 5.38; Br, 32.68.

Poly[3-(12-bromododecyl)thiophene] (2). The polymerization was carried out as described above for 1 except the reaction time was $2.5 \mathrm{~h}$. 12-(3-Thienyl)-1-bromododecane (4) (0.300 g; $0.906 \mathrm{mmol})$ in $5 \mathrm{~mL}$ of freshly distilled $\mathrm{CHCl}_{3}$ was added to a stirred solution of anhydrous $\mathrm{FeCl}_{3}(0.591 \mathrm{~g} ; 3.63 \mathrm{mmol})$ in $20 \mathrm{~mL}$ of freshly distilled $\mathrm{CHCl}_{3} 2$ was obtained as a dark red powder (0.236 g; 80\%). ${ }^{1} \mathrm{H}$ NMR $\delta: 6.98$ (br, $\left.1 \mathrm{H}\right), 3.39$ (t, $\left.2 \mathrm{H}\right), 2.81$ and 2.60 (br, $\left.2 \mathrm{H}\right), 1.88$ 1.28 (br, $20 \mathrm{H}$ ), 0.85 (br, small peaks, about $2 \%$ ). ${ }^{13} \mathrm{C}$ NMR $\delta: 139.9,133.7,130.5,128.6,33.9$, 32.8, 30.5, 29.5 (br), 29.46 (br), 28.8, 28.2. IR (KBr, cm $\left.{ }^{-1}\right): 3053,2922,2851,1511,1462,1262$, 1097, 1021, 822, 803, 721, 645, 563. UV-vis (THF) $\lambda_{\max } 438 \mathrm{~nm}$, band edge $530 \mathrm{~nm}$; Film (cast from THF) $\lambda_{\max } 505,570(\mathrm{sh}), 610(\mathrm{sh}) \mathrm{nm}$, band edge $670 \mathrm{~nm}$. GPC analysis: $\overline{\mathrm{M}}_{\mathrm{n}}=91,100$ $(\mathrm{PDI}=1.7)$. Fluorescence: THF solution $\lambda_{\text {Emission max }}=576 \mathrm{~nm}$ and film (cast from THF) $\lambda_{\text {Emission }}$ $\max =680$ at excitation wavelengths of $530 \mathrm{~nm}$ and $400 \mathrm{~nm}$, respectively. Anal. Calcd. for $\left(\mathrm{C}_{16} \mathrm{H}_{25} \mathrm{SBr}\right)_{\mathrm{n}}$ : C, 58.35; H, 7.65; Br, 24.26. Found: C, 57.98; H, 7.76; Br, 24.10; Fe, 0.03\%.

Doping of 1 and 2. Thin films, deep red-burgundy in color, of the polymers 1 and $\mathbf{2}$ were cast onto glass slides from a dilute solution of the polymer in xylene. They were then oxidized into their electronically conductive form, which was dark blue in color, by two methods. 1) The polymer/substrate was immersed into a nitromethane solution containing $0.05 \mathrm{M}$ anhydrous $\mathrm{FeCl}_{3}$ for $50 \mathrm{~min}$, rinsed with nitromethane and dried in vacuum before the electrical conductivity measurement. 2) The polymer/substrate was exposed to $I_{2}$ vapor for $24 \mathrm{~h}$ at room temperature, then excess iodine was removed under vacuum for 5-10 min. Doping of a 3.1 $\mu \mathrm{m}$ thick film of polymer 1 with $\mathrm{FeCl}_{3}$ gave $\sigma=7.5 \mathrm{~S} \mathrm{~cm}^{-1}$ and of a $2.7 \mu \mathrm{m}$ thick film with $\mathrm{I}_{2}$ gave $\sigma$ 
$=18 \mathrm{~S} \mathrm{~cm}^{-1}$. Doping of a $4.0 \mu \mathrm{m}$ thick film of polymer 2 with $\mathrm{FeCl}_{3}$ gave $\sigma=46 \mathrm{~S} \mathrm{~cm}^{-1}$ and of a $2.5 \mathrm{~m}$ thick film with $\mathrm{I}_{2}$ gave $\sigma=32 \mathrm{~S} \mathrm{~cm}^{-1}$.

Poly[3-(6-iodohexyl)thiophene] (8). Poly[3-(6-iodohexyl)thiophene] (8) was obtained by a modification of the Finkelstein reaction ${ }^{9}$ from 1. The solvent selection was critical for the completion of substitution of bromine by iodide. A solubility study showed that $\mathbf{1}$ was completely soluble in $\mathrm{CHCl}_{3}$ and insoluble in acetone, while sodium iodide was soluble in acetone and insoluble in $\mathrm{CHCl}_{3}$. However, both 1 and $\mathrm{NaI}$ were soluble in a mixture of $\mathrm{CHCl}_{3}$ and acetone in the ratio of 3.8 to 1 . Poly[3-(6-bromohexyl)thiophene] (1; $30.0 \mathrm{mg} ; 0.120 \mathrm{mmol})$ and $\mathrm{CHCl}_{3}(25 \mathrm{~mL})$ were placed in a $100 \mathrm{~mL}$ three-necked round bottomed flask equipped with magnetic stirrer, and nitrogen inlet. A solution of $\mathrm{NaI}(0.18 \mathrm{~g}, 1.22 \mathrm{mmol})$ in acetone $(6.50 \mathrm{~mL})$ was prepared in a small vial. The $\mathrm{CHCl}_{3}$ and acetone were dried over $4 \AA$ molecular sieves before they were used. To the flask containing $1 / \mathrm{CHCl}_{3}$ was added the $\mathrm{NaI} / \mathrm{Me}_{2} \mathrm{CO}$ solution via syringe. The mixture was heated at $65{ }^{\circ} \mathrm{C}$ for $22 \mathrm{~h}$, then $3 \mathrm{~mL}$ of acetone was added and the mixture was heated for an additional $24 \mathrm{~h}$ at $65{ }^{\circ} \mathrm{C}$. The solvent was removed in vacuum and 50 $\mathrm{mL}$ of $\mathrm{CHCl}_{3}$ was added. The solution was washed four times with water, dried $\left(\mathrm{MgSO}_{4}\right)$ and the solvent was removed in vacuum to give dark red poly[3-(6-iodohexyl)thiophene] (8). Further purification was done by adding a concentrated $\mathrm{CHCl}_{3}$ solution of $\mathbf{8}$ to $40 \mathrm{~mL}$ of methanol from which $32.9 \mathrm{mg}(92 \%)$ of 8 was obtained. ${ }^{1} \mathrm{H}$ NMR $\delta: 6.98(\mathrm{~m}, 1 \mathrm{H}), 3.43(\mathrm{~m}$, about 2-3\%, this peak belongs to $-\mathrm{CH}_{2} \mathrm{Br}$ of 1), $3.21(\mathrm{~m}, 2 \mathrm{H}), 2.51-2.89$ (br m, $\left.2 \mathrm{H}\right), 1.20-1.92(\mathrm{~m}, 8 \mathrm{H})$. Integration of the peaks at $\delta 3.43\left(-\mathrm{CH}_{2} \mathrm{Br}\right)$ and $\delta 3.21\left(-\mathrm{CH}_{2} \mathrm{I}\right)$ indicated $>97 \%$ of the bromine had been displaced by iodide. ${ }^{13} \mathrm{C}$ NMR $\delta$ : 7.3, 28.5, 29.4, 29.8, 30.4, 33.5, 128.7, 130.7, 133.8, 139.7. IR (KBr), $\left.\mathrm{cm}^{-1}\right) 3398,2924,2853,1740,1607,1515,1460,1393,1365,1311,1249,1162$, 1099, 823, 755, 721, 651, 589. UV-vis (THF) $\lambda_{\max } 430 \mathrm{~nm}$; Film (cast from THF) $\lambda_{\max } 478 \mathrm{~nm}$. Anal. Calcd. for $\mathrm{C}_{10} \mathrm{H}_{13} \mathrm{IS}$ : C, 41.11; H, 4.48. Found: C, 44.96; H, 4.94. ${ }^{29}$

6-(3-Thienyl)-1-hexyl $S$-thioacetate (9a). Potassium thioacetate $(0.420 \mathrm{~g}, 3.66 \mathrm{mmol})$ and absolute ethanol $(20 \mathrm{~mL})$ were put into a $50 \mathrm{~mL}$ three-necked round bottomed flask equipped with a magnetic stirrer, and nitrogen inlet. To the flask was added $0.650 \mathrm{~g}(2.60 \mathrm{mmol})$ of 6-(3thienyl)-1-bromohexane (3), the mixture was stirred for $5 \mathrm{~h}$ under reflux and then cooled to ambient temperature. The product was extracted with diethyl ether $(4 \times 50 \mathrm{~mL})$, the combined extracts were washed with water $(4 \times 5 \mathrm{~mL})$ and dried $\left(\mathrm{MgSO}_{4}\right)$. After filtration, the ether was removed in vacuum and the light yellow crude product was purified by silica gel flash column chromatography using hexane/ethyl acetate $(33: 1 \mathrm{v} / \mathrm{v})$ as eluent. The yield of 6-(3-thienyl)-1hexyl $S$-thioacetate (9a) was $0.400 \mathrm{~g}(70 \%)$ as a colorless liquid (HPLC purity $>98 \%, t_{R}=4.09$ $\min ) .{ }^{1} \mathrm{H}$ NMR $\delta: 1.30-1.50(\mathrm{~m}, 4 \mathrm{H}), 1.50-1.70(\mathrm{~m}, 4 \mathrm{H}), 2.32(\mathrm{~s}, 3 \mathrm{H}), 2.62(\mathrm{t}, 2 \mathrm{H}, \mathrm{J}=8 \mathrm{~Hz})$, $2.86(\mathrm{t}, 2 \mathrm{H}, J=8 \mathrm{~Hz}), 6.87-6.95(\mathrm{~m}, 2 \mathrm{H}), 7.20-7.24(\mathrm{~m}, 1 \mathrm{H}) .{ }^{13} \mathrm{C}$ NMR $\delta: 28.6,28.7,29.1$, 29.4, 30.1, 30.3, 30.6, 120.1, 125.3, 128.4, 143.2, 196.2. IR (neat, $\mathrm{cm}^{-1}$ ): 3103, 3054, 2929, 2855 , $1691,1536,1458,1354,1298,1239,1134,954,859,834,773,628,530$. Anal. Calcd. for $\mathrm{C}_{12} \mathrm{H}_{18} \mathrm{OS}_{2}$ : C, 59.46; H, 7.48. Found: C, 59.07; H, 7.53.

12-(3-Thienyl)-1-dodecyl $S$-thioacetate (9b). Potassium thioacetate $(0.420 \mathrm{~g}, 3.66 \mathrm{mmol})$ and absolute ethanol $(20 \mathrm{~mL})$ were put into a $50 \mathrm{~mL}$ three-necked round bottomed flask equipped 
with a magnetic stirrer, and nitrogen inlet. To the flask was added $0.880 \mathrm{~g}$ (2.66 mmol) of 12-(3thienyl)-1-bromododecane (4). The product was obtained in the same manner as described for 9a, as a colorless liquid (HPLC purity $>97 \%, t_{R}=6.69 \mathrm{~min}$ ). The crude product was purified by silica gel flash column chromatography using hexane/ethyl acetate $(100: 1 \mathrm{v} / \mathrm{v})$ as eluent to yield $0.444 \mathrm{~g}(51 \%)$ of $9 \mathrm{~b} .{ }^{1} \mathrm{H}$ NMR $\delta: 1.20-30(\mathrm{~m}, 16 \mathrm{H}), 1.50-1.65(\mathrm{~m}, 4 \mathrm{H}), 2.30(\mathrm{~s}, 3 \mathrm{H}), 2.61(\mathrm{t}, 2$ $\mathrm{H}, J=8 \mathrm{~Hz}), 2.85(\mathrm{t}, 2 \mathrm{H}, J=8 \mathrm{~Hz}), 6.85-6.93(\mathrm{~m}, 2 \mathrm{H}), 7.10-7.23(\mathrm{~m}, 1 \mathrm{H}) .{ }^{13} \mathrm{C}$ NMR $\delta: 28.8$, $29.1_{0}, 29.1_{4}, 29.3,29.4_{4}, 29.4_{8}, 29.5_{3}, 29.5_{5}, 29.5_{8}, 30.3,30.5,30.6,119.7,125.0,128.3,143.2$, 196.0. IR (neat, $\mathrm{cm}^{-1}$ ): 3104, 3051, 2925, 2853, 1693, 1536, 1460, 1410, 1352, 1134, 1108, 953, 857, 834, 773, 722, 627. Anal. Calcd. for $\mathrm{C}_{18} \mathrm{H}_{30} \mathrm{OS}_{2}$ : C, 66.21; H, 9.26. Found: C, 65.84; H, 9.53 .

Poly[6-(3-thienyl)-1-hexyl $S$-thioacetate] (10a). Was prepared by a method similar to that used for the preparation of poly[3-(6-bromohexyl)thiophene] (1). $0.180 \mathrm{~g}$ of 6-(3-thienyl)-1-hexyl $S$ thioacetate $(9 \mathbf{a} ; 0.740 \mathrm{mmol})$ in $3 \mathrm{~mL}$ of freshly distilled $\mathrm{CHCl}_{3}$ was added to a stirred solution of anhydrous $\mathrm{FeCl}_{3}(0.480 \mathrm{~g} ; 2.96 \mathrm{mmol})$ in $15 \mathrm{~mL}$ of freshly distilled $\mathrm{CHCl}_{3}$ The reaction was carried out for $1.75 \mathrm{~h}$ at ambient temperature. The brown precipitate of 10a was washed with methanol several times then put into $100 \mathrm{~mL}$ of $\mathrm{CHCl}_{3}$ and $3 \mathrm{~mL}$ of $30 \%$ ammonium hydroxide was added. The brown 10a changed to a red-orange color immediately upon ammonium hydroxide addition. The polymer was dried under vacuum for $24 \mathrm{~h}$ and yielded $0.109 \mathrm{~g}(61 \%)$ of 10a which was insoluble in $\mathrm{CHCl}_{3}$, THF, DMSO, $\mathrm{CH}_{3} \mathrm{OH}$, toluene, o-dichlorobenzene or tetramethylene sulfone, and very slightly soluble in refluxing thiophene $\left(84{ }^{\circ} \mathrm{C}\right) \cdot{ }^{13} \mathrm{C} \mathrm{CP}-\mathrm{MAS}$ NMR (10 kHz spinning speed): $\delta$ 20-45 (br), 120-145 (br). IR (KBr, cm ${ }^{-1}$ ): 3058, 2926, 2852, $1688,1518,1457,1351,1264,1186,1132,951,833,726,627$. Anal. Calcd. for $\mathrm{C}_{12} \mathrm{H}_{16} \mathrm{OS}_{2}$ : C, 59.96; H, 6.71; S, 26.67. Found: C, 59.73; H, 6.78; S, 26.54. The pressed pellet conductivities for polymer 10a, obtained as described for polymers 1 and 2 , but on pellets pressed in a $\mathrm{KBr}$ IR die, were $\sigma=4 \times 10^{-5} \mathrm{Scm}^{-1}$ doped with $\mathrm{FeCl}_{3}$ and $\sigma=8 \times 10^{-5} \mathrm{Scm}^{-1}$ doped with $\mathrm{I}_{2}$.

Poly[12-(3-thienyl)-1-dodecyl $S$-thioacetate] (10b). Was prepared by a method similar to that used for the preparation of 10a. $0.040 \mathrm{~g}$ of 12-(3-thienyl)-1-dodecyl $S$-thioacetate $(\mathbf{9 b} ; 0.123$ mmol) in $2.5 \mathrm{~mL}$ of freshly distilled $\mathrm{CHCl}_{3}$ was added to a stirred solution of anhydrous $\mathrm{FeCl}_{3}$ ( $0.080 \mathrm{~g} ; 0.490 \mathrm{mmol})$ in $5 \mathrm{~mL}$ of freshly distilled $\mathrm{CHCl}_{3}$ The reaction was carried out for $1.75 \mathrm{~h}$ at ambient temperature. The dark purple-brown mixture was poured into $100 \mathrm{~mL}$ of methanol. The solid product was filtered and washed with methanol several times, then $150 \mathrm{~mL}$ of $\mathrm{CHCl}_{3}$ was added followed by $0.20 \mathrm{~mL}$ of anhydrous hydrazine. The green-brown color changed to a red-orange color immediately upon $\mathrm{NH}_{2} \mathrm{NH}_{2}$ addition. The polymer $\mathbf{1 0 b}$ was dried under vacuum for $24 \mathrm{~h}$ and yielded $0.020 \mathrm{~g}(50 \%)$ of $\mathbf{1 0 b}$ which was insoluble in $\mathrm{CHCl}_{3}, \mathrm{THF}, \mathrm{DMSO}, \mathrm{CH}_{3} \mathrm{OH}$, acetone, toluene, $o$-dichlorobenzene and tetramethylene sulfone, and very slightly soluble in refluxing thiophene $\left(84{ }^{\circ} \mathrm{C}\right) .{ }^{13} \mathrm{C} \mathrm{CP}-\mathrm{MAS}$ NMR $(5 \mathrm{kHz}$ spinning speed): $\delta 20-45$ (br), 120-145 (br). IR (KBr, cm ${ }^{-1}$ ): 2922, 2850, 1639, 1459, 1090, 1169, 831, 721. Anal. Calcd. for $\mathrm{C}_{18} \mathrm{H}_{28} \mathrm{OS}_{2}$ : C, 66.62; H, 8.70; S, 19.76. Found: C, 66.12; H, 8.81; S, 19.57.

Poly[3-(6-mercaptohexylthiophene)] (11). Was synthesized by using a post-polymerization process. $80.0 \mathrm{mg}(0.330 \mathrm{mmol})$ of poly[3-(6-bromohexylthiophene)] 1 was dissolved in $20 \mathrm{~mL}$ of 
$\mathrm{CHCl}_{3} .40 .0 \mathrm{mg}(0.520 \mathrm{mmol})$ of thiourea was dissolved in $10 \mathrm{~mL}$ of EtOH and both solutions were combined in a $50 \mathrm{~mL}$ three-necked flask equipped with a magnetic stirring bar, condenser capped with a drying tube and nitrogen inlet. The reaction mixture was stirred for $24 \mathrm{~h}$ under reflux, cooled to room temperature and the solvent was removed in vacuo. $20 \mathrm{~mL}$ of $\mathrm{CHCl}_{3}$ and $6 \mathrm{~mL}$ of saturated $\mathrm{Na}_{2} \mathrm{CO}_{3}$ were added and the mixture was stirred under nitrogen at room temperature for $24 \mathrm{~h}$. The product 11 was separated and washed with an aqueous $\mathrm{HCl}$ solution $(\mathrm{pH}=4.00)$, methanol and dried under vacuum. The red powder of 11 was insoluble in $\mathrm{CHCl}_{3}$, THF, DMF, DMSO, toluene, xylene, $o$-dichlorobenzene and very slightly soluble in refluxing thiophene $\left(84{ }^{\circ} \mathrm{C}\right) .{ }^{13} \mathrm{C}$ CP-MAS NMR (5 kHz spinning speed): $\delta$ 20-45 (br), 120-145 (br). IR $\left(\mathrm{KBr}, \mathrm{cm}^{-1}\right): 3059,2927,2853,1711,1519,1459,1367,1261,1195,1129,1039,833,724,667$, 603. Anal. Calcd. for $\mathrm{C}_{10} \mathrm{H}_{14} \mathrm{~S}_{2}$ : C, 60.56; H, 7.11; S, 32.33. Found: C, 60.23; H, 7.28; S, 31.94. The pressed pellet conductivities for polymer 11, obtained as described for polymers $\mathbf{1}$ and $\mathbf{2}$, but on pellets pressed in a $\mathrm{KBr}$ IR die, were $\sigma=2.3 \times 10^{-2} \mathrm{Scm}^{-1}$ doped with $\mathrm{FeCl}_{3}$ and $\sigma=0.44 \mathrm{Scm}^{-1}$ doped with $\mathrm{I}_{2}$.

Attempted hydrolysis of 10a. $0.02 \mathrm{~g}(0.083 \mathrm{mmol})$ of poly[6-(3-thienyl)-1-hexyl $S$-thioacetate] 10a, $5 \mathrm{~mL}$ of $2 \mathrm{M} \mathrm{KOH}$ solution and $10 \mathrm{~mL}$ of $\mathrm{CH}_{2} \mathrm{Cl}_{2}$ were placed in a $50 \mathrm{~mL}$ three-necked round bottomed flask equipped with a magnetic stirrer and nitrogen inlet. The mixture was refluxed for $32 \mathrm{~h}$ and the solid material did not go into solution during this time. After hydrolysis, the solid was filtered and its IR spectrum was identical to that of the starting material 10a. Another hydrolysis experiment was performed using $0.5 \mathrm{~g} \mathrm{NaBH}_{4}$ in $5 \mathrm{~mL}$ of $1 \mathrm{M} \mathrm{KOH}$ and $10 \mathrm{~mL}$ of $\mathrm{C}_{2} \mathrm{H}_{5} \mathrm{OH}$. This reaction was carried out for $48 \mathrm{~h}$ under reflux. The solid material 10a did not go into solution during the hydrolysis process and after hydrolysis, the product again was shown to be the starting material 10a by IR spectroscopy.

\section{Summary}

We have prepared poly[3-(6-bromohexyl)thiophene] (1) and poly[3-(12bromododecyl)thiophene] (2) by $\mathrm{FeCl}_{3}$ polymerization of the corresponding monomers and they show $81 \%$ head-to-head regioregularity. Poly[3-(6-iodohexyl)thiophene] (8) was prepared by $\mathrm{S}_{\mathrm{N} 2}$ displacement on 1. Conductivities, up to $46 \mathrm{Scm}-1$, of the doped polymers were measured for 1 and 2. The $\mathrm{S}_{\mathrm{N} 2}$ displacement reaction was $>97 \%$ complete as shown by NMR spectroscopy. Further, $\mathrm{S}_{\mathrm{N} 2}$ reactions provided polymers with sulfur substituted in the $\omega$-position of the alkyl groups, namely poly[6-(3-thienyl)-1-hexyl $S$-thioacetate] (10a), poly[12-(3-thienyl)-1-dodecyl $S$ thioacetate] (10b) and poly[3-(6-mercaptohexylthiophene)] (11). These were insoluble in organic solvents, possibly due to their relatively high molecular weights. The ${ }^{13} \mathrm{C} C P-M A S$ spectra were obtained along with pressed pellet conductivities of up to $0.44 \mathrm{Scm}-1$ for the doped polymers. TGA was obtained for several of these polymers and they show thermal decomposition in two stages. 


\section{Acknowledgments}

We thank the Welch Foundation (Grant Y-1407) for their generous financial support. We also thank Dr. Kelly L. Moran of Bruker Instruments, Billerica, MA for obtaining the CP-MAS NMR spectra.

\section{References and Notes}

1. Reynolds, J. R.; Pomerantz, M. In Electroresponsive Molecular and Polymeric Systems; Skotheim, T. A., Ed.; Dekker: New York, 1991; Vol. 2, Chapter 4, pp 187.

2. Roncali, J. In Handbook of Conducting Polymers, $2^{\text {nd }}$ Ed; Skotheim, T.; Elsenbaumer, R. L., Reynolds, J. R., Eds.; Dekker: New York, 1998; Chapter 12, pp 311.

3. McCullough, R. D.; Ewbank, P. C. In Handbook of Conducting Polymers, $2^{\text {nd }}$ Ed; Skotheim, T., Elsenbaumer, R. L., Reynolds, J. R., Eds.; Dekker: New York, 1998; Chapter 9, pp 225258.

4. Pomerantz, M.; Liu, M. L. Polym. Prepr. (Am. Chem. Soc., Div. Polym. Chem.) 1998, 39(1), 153.

5. Pomerantz, M.; Liu, M. L. Synth. Met. 1999, 101, 95.

6. Iraqi, A.; Crayston, J. A.; Walton, J. C. J. Mater. Chem. 1998, 8, 31.

7. Ng, S. C.; Ma, Y. F.; Chan, H. S. O.; Dou, Z. L. Synth. Met. 1999, 100, 269.

8. Zhai, L.; Pilston, R. L.; Zaiger, K. L.; Stokes, K. K.; McCullough, R. D. Macromolecules 2003, 36, 61.

9. Bäuerle, P.; Würthner, F.; Heid, S. Angew. Chem., Int. Ed. Engl. 1990, 29, 419.

10. Iyer, R. R.; Mamdapur, V. R. Indian J. Chem. 1989, 28B, 728.

11. Joshi, N. N.; Mamdapur, V. R.; Chadha, M. S. Tetrahedron 1984, 40, 3285.

12. Bongini, A.; Cardillo, G.; Orena, M.; Sandri, S. Synthesis 1979, 618.

13. Smith, L. H. Organic Syntheses; Wiley \& Sons: New York, 1955; Coll. Vol. 3, pp 793.

14. Mao, H.; Xu, B.; Holdcroft, S. Macromolecules 1993, 26, 1163.

15. Sato, M.; Morii, H. Macromolecules 1991, 24, 1196.

16. Hotta, S.; Soga, M.; Sonoda, N. Synth. Met. 1988, 26, 267.

17. Hotta, S. Synth. Met. 1987, 22, 103.

18. Nowack, M. J.; Rughooputh, S. D. D. V.; Heeger, A. J.; Wudl, F. Macromolecules 1987, 20, 965.

19. McCullough, R. D.; Lowe, R. D.; Jayaraman, M.; Anderson, D. L. J. Org. Chem. 1993, 58, 904.

20. Smith, M. B.; March, J. March's Advanced Organic Chemistry; Wiley \& Sons: New York, 2001; p 517.

21. Kagabu, S.; Prinzbach, H. Angew. Chem., Int. Ed. Engl. 1975, 14, 252.

22. Prinzbach, H.; Kaiser, C.; Fritz, H. Angew. Chem., Int. Ed. Engl. 1975, 14, 253. 
23. Smith, M. B.; March, J. March's Advanced Organic Chemistry; Wiley \& Sons: New York, 2001; p 495.

24. Silverstein, R. M.; Webster, F. X. Spectrometric Identification of Organic Compounds; 6th eds; Wiley \& Sons: New York, 1998; p 106.

25. van der Pauw, L. J. Philips Tech. Rev. 1958-1959, 20, 220.

26. Elsenbaumer, R. L.; Shacklette, L. W. In Handbook of Conducting Polymers; Skotheim, T. A., Ed.; Marcel Dekker: New York, 1986; Vol. 1, Chapter 6.

27. Iyer, R. R.; Mamdapur, V. R. Indian J. Chem. 1986, 25B, 1216.

28. Ng, S. C.; Fu, P.; Yu, W.-L.; Chan, H. S. O.; Tan, K. L. Synth. Met. 1997, 87, 119.

29. It should be pointed out that halogenated polymers are difficult to combust and frequently do not give proper elemental combustion analysis. Indeed there are many halogenated polymers which are used as flame retardants. Lyons, J. W. The Chemistry and Uses of Fire Retardants; Wiley \& Sons: New York; 1976; Chapter 7. 